Review

\title{
Domestic animal proteomics in the 21st century: A global retrospective and viewpoint analysis
}

\author{
André M. Almeida ${ }^{a, *}$, Syed Azmal Ali ${ }^{\mathrm{b}}$, Fabrizio Ceciliani ${ }^{\mathrm{c}}$, P. David Eckersall ${ }^{\mathrm{d}}$, \\ Lorenzo E. Hernández-Castellano $^{\text {e,f }}$, Rongwei Han ${ }^{g}$, Jaka J. Hodnik ${ }^{\mathrm{h}}$, Shalini Jaswal ${ }^{\mathrm{b}}$, \\ John D. Lippolis ${ }^{\mathrm{i}}$, Mark McLaughlin ${ }^{\mathrm{d}}$, Ingrid Miller ${ }^{\mathrm{j}}$, Ashok Kumar Mohanty ${ }^{\mathrm{b}}$,
} Vladimir Mrljak ${ }^{\mathrm{k}}$, Jarlath E. Nally ${ }^{\mathrm{i}}$, Paolo Nanni ${ }^{1}$, Jeffrey E. Plowman ${ }^{\mathrm{m}}$, Mirele D. Poleti ${ }^{\mathrm{n}}$, David M. Ribeiro ${ }^{a}$, Pedro Rodrigues ${ }^{\circ}$, Bernd Roschitzki ${ }^{1}$, Ralph Schlapbach ${ }^{1}$, Jože Starič ${ }^{\mathrm{h}}$, Yongxin Yang ${ }^{\mathrm{g}}$, Maya Zachut $^{\mathrm{p}}$

${ }^{\text {a } L E A F, ~ I n s t i t u t o ~ S u p e r i o r ~ d e ~ A g r o n o m i a, ~ U n i v e r s i d a d e ~ d e ~ L i s b o a, ~ 1349-017 ~ L i s b o a, ~ P o r t u g a l ~}$

${ }^{\mathrm{b}}$ Proteomics and Cell Biology Lab, Animal Biotechnology Center, National Dairy Research Institute, Karnal 132001, Haryana, India

c Dipartimento di Medicina Veterinaria, Università degli Studi di Milano, 20133 Milano, Italy

${ }^{\mathrm{d}}$ Institute of Biodiversity, Animal Health and Comparative Medicine, University of Glasgow, Glasgow G61 1QH, United Kingdom

${ }^{\mathrm{e}}$ Department of Animal Science, AU-Foulum, Aarhus University, 8830 Tjele, Denmark

${ }^{\mathrm{f}}$ Animal Production and Biotechnology group, Institute of Animal Health and Food Safety, Universidad de Las Palmas de Gran Canaria, 35413 Arucas, Spain.

${ }^{\mathrm{g}}$ College of Food Science and Engineering, Qingdao Agricultural University, Qingdao 266109, China

${ }^{\mathrm{h}}$ Veterinary Faculty, Clinic for Reproduction and Large Animals - Section for Ruminants, University of Ljubljana, 1000 Ljubljana, Slovenia

${ }^{\mathrm{i}}$ Ruminant Diseases and Immunology Research Unit, USDA, Agricultural Research Service, National Animal Disease Center, Ames, Iowa 50010, United States

${ }^{\mathrm{j}}$ Institute of Medical Biochemistry, University of Veterinary Medicine, Veterinaerplatz 1, A-1210 Vienna, Austria

${ }^{\mathrm{k}}$ ERA Chair FP7, Internal Diseases Clinic, Faculty of Veterinary Medicine, University of Zagreb, Zagreb, Croatia

${ }^{1}$ Functional Genomics Center Zurich, Swiss Federal Institute of Technology ETH Zurich / University of Zurich, Winterthurerstr. 190,8057 Zurich, Switzerland

${ }^{\mathrm{m}}$ AgResearch, 1365 Springs Rd, Lincoln 7674, New Zealand

${ }^{\mathrm{n}}$ FZEA - Faculty of Animal Science and Food Engineering, University of São Paulo, Avenida Duque de Caxias Norte - 225, 13635-900 Pirassununga, SP, Brazil

${ }^{\circ}$ CCMAR - Centre of Marine Sciences of Algarve, University of Algarve, Campus de Gambelas, 8005-139 Faro, Portugal

${ }^{\mathrm{p}}$ Department of Ruminant Science, Institute of Animal Sciences, Agricultural Research Organization/Volcani Center, Rishon Lezion 7505101, Israel

\section{A R T I C L E I N F O}

\section{Keywords:}

Proteomics

Animal science

Veterinary science

Developments

Drawbacks

\begin{abstract}
A B S T R A C T
Animal production and health are of significant economic importance, particularly regarding the world food supply. Animal and veterinary sciences have evolved immensely in the past six decades, particularly in genetics, nutrition, housing, management and health. To address major challenges such as those posed by climate change or metabolic disorders, it is of utmost importance to use state-of-the-art research tools. Proteomics and the other post-genomic tools (transcriptomics or metabolomics) are among them. Proteomics has experienced a considerable development over the last decades. This brought developments to different scientific fields. The use and adoption of proteomics tools in animal and veterinary sciences has some limitations (database availability or access to proteomics platforms and funding). As a result, proteomics' use by animal science researchers varies across the globe. In this viewpoint article, we focus on the developments of domestic animal proteomics over the last decade in different regions of the globe and how the researchers have coped with such challenges. In the second part of the article, we provide examples of funding, educational and laboratory establishment initiatives designed to foster the development of (animal-based) proteomics. International scientific collaboration is a definitive and key feature in the development and advancement of domestic animal proteomics.

Significance: Animal production and health are very important for food supply worldwide particularly as a source of proteinaceous foods. Animal and veterinary sciences have evolved immensely in the last decades. In order to address the major contemporary challenges facing animal and veterinary sciences, it is of utmost importance to use state-of-the-art research tools such as Proteomics and other Omics. Herein, we focus on the major developments in domestic animal proteomics worldwide during the last decade and how different regions of the
\end{abstract}

\footnotetext{
* Corresponding author.

E-mail address: aalmeida@isa.ulisboa.pt (A.M. Almeida).
} 
world have used the technology in this specific research field. We address also major international efforts aiming to increase the research output in this area and highlight the importance of international cooperation to address specific problems inherent to domestic animal proteomics.

\section{Introduction}

Animal production and animal health are two very important economic sectors worldwide. These two sectors have additionally a crucial importance in protein supply for human nutrition and well-being. The domestic animal industries, including farm animal production along with companion animal nutrition and health have witnessed considerable improvements over the last six decades. These are unmatched to any other period of human history, except perhaps for the domestication processes that occurred in some cases over 10,000 years ago. Such progress could only be possible through the application of knowledge and techniques developed over the years and based on both empiric and scientific research. Indeed, developments in the field of genetics, nutrition, physiology, reproduction, among many other disciplines, have allowed domestic (production and companion) animal science and health to achieve the high level we all know today.

Over the last three decades, the so-called post-genomic tools, including transcriptomics, metabolomics and particularly proteomics have slowly developed and been increasingly integrated in research in a considerable variety of fields including human health, plant science or environmental research, to name but a few. Specifically related to domestic animal science, numerous applications may be found, covering areas from meat and dairy science [1], to food safety and traceability [2] related to animal-borne disease research [3], as well as wool science [4], and many others. Furthermore, proteomic research has been undertaken in most domestic species including fish [5], cats [6], dogs [7], cattle [8], small ruminants $[9,10]$, rabbits [11], pigs $[12,13]$ and poultry [14]. The results obtained from such research have contributed significantly to both fundamental and applied knowledge in the field [15] being of utmost importance to the advancement of animal and veterinary sciences.

From the initial stages of development of two-dimensional electrophoresis and mass spectrometry (MS) in the mid-1970s and from the mid-1980s under the new term "proteomics", [16-18] until the early 2010 s, proteomics was essentially based on a combination of two technologies: the use of two-dimensional gels coupled to protein identification using MS [15]. Nevertheless, the panorama quickly changed and developments in MS rapidly led to the establishment and widespread use of gel-free proteomics in a multitude of different scientific fields. Such methods became increasingly available and of particular relevance, at prices that became more and more affordable. The last decade brought to proteomics a further push in the use of MS. It expanded the already existing panel of methods, for instance by developing targeted proteomics (selected reaction monitoring SRM/multiple reaction monitoring MRM [19]) or top-down proteomics (analysis of complete proteins instead of peptides thereof [20]) and even heading for single cell proteomics [21]. Sensitivity was further increased, and detection and study of PTMs (mainly phosphorylation and glycosylation, but also others) in connection with health and disease gained importance. The latter is a field where two-dimensional electrophoresis can still compete as a research tool and provide good clues, allowing separation and easy visualization of proteoforms, even if MS will be the tool to identify the proteins present in the spots of interest. In addition, the range of proteomic applications has broadened and its increased use in domestic animal sciences has been no exception.

Indeed, though initially the use of proteomics in domestic animal science was rather limited, over the last decade it became a regular tool, being incorporated in a considerable variety of domestic animal research projects. Similar to developments in other research fields, such use grew from an approach essentially based on two-dimensional electrophoresis coupled to MS to an approach based on large-scale gelfree proteomics analysis. At the European level at least, such development coincided with the onset of COST (Cooperation in Science and Technology) action FA1002 - Farm Animal Proteomics (https://www. cost.eu/actions/FA1002/\#tabs|Name:overview) in early 2011, roughly 10 years ago. These projects are multinational research networking projects that focus on developing a specific research field. COST actions are funded by the European Science Foundation and provide funds for scientific networking efforts such as STSMs (Short Term Scientific Missions), the organization of research conferences or scientific editing and publications. COST action FA1002 was the basis of a very effective scientific network in the field of animal proteomics and led to extensive collaborations. The collaborations were not just at the European level, but further research collaborations were extended to other countries including Australia, New Zealand, South Africa, Argentina (COST associated countries) and others such as Canada, the USA and Thailand. The outputs of COST action FA1002 were vast and included a special issue of the Journal of Proteomics published in 2012 with 28 articles (https://www.sciencedirect.com/journal/journal-ofproteomics/vol/75/issue/14) [22] and a book on farm animal proteomics published in 2018 [23]. Above all, it paved the way for very significant research projects at the national, EU and third country levels, furthermore contributing to the widespread use of proteomics through access to high-throughput Omics platforms.

Within the context of the growing importance of domestic animal proteomics and celebrating the 10th anniversary of the establishment of COST action FA1002, several of us proposed to the editorial board of the Journal of Proteomics to issue a new special collection dedicated to this topic (https://www.sciencedirect.com/journal/journal-of-proteom ics/special-issue/10ZLKC26J9F). Twenty-seven articles from all over the world were submitted to peer-review making up such a thematic issue. Given the global interest in the development of domestic animal proteomics, we have also written the present viewpoint analysis paper focusing on the major events in the development of domestic animal proteomics. We ultimately aim to provide a global perspective to ascertain how domestic animal proteomics is conducted in different regions of the world and have hence invited specialists in the field from different major regions: North America, South America, Australia and New Zealand, China, India and Israel in addition to Europe. Regarding this latter continent, we have decided to focus on the major divergences occurring between North and South and between East and West. These countries and regions show considerable differences, either geographic or in population. They are at different stages concerning the use of Proteomics and other Omics as a tool of use in domestic animal research. As such, the different sections show different contexts that led to some heterogeneity in the way these sections are presented. Indeed, for New Zealand or Israel for instance, it was possible to pinpoint the major research efforts in this very specific field, while for other large-size regions like Europe, or North or South America, this would have been much more difficult given the amount of references available. Finally, there are two other countries in our analysis that are of a considerable size and research dimension: India and China. As will be seen, the use of proteomics in these two countries is relatively recent. However, the amount and diversity of work that has been achieved in these two countries in recent years, led us to show these sections in a more descriptive way and emphasizing the major achievements in the field.

We also included case studies that focused on specific programs targeting the development of domestic animal proteomics. These included for instance the ERA Chair project of the EU's Widening program that established a high level proteomics laboratory at the 
Veterinary Faculty of the University of Zagreb in Croatia and the transEuropean Marie Curie MANNA Doctoral program. Furthermore, technical introductory courses that took place in Thailand which were provided by European specialists and that started with the personal initiatives and collaborations between scientists, have been included. While conducting this overall analysis, it was impossible to include all the regions of the world, so we have opted to provide an emphasis on those where domestic animal proteomics is well implemented. By doing so, it was inevitable that some particular regions would be left out. Nevertheless, it is likely that such regions may become relevant players in the domestic animal proteomics community in the future.

\section{Domestic animal proteomics in the USA in recent years}

Proteomics is used as a research tool for agricultural sciences in the United States of America, but its limited application falls short of its potential, and notably with farm animal proteomics [24]. There are relatively few United States of America research laboratories who publish in the area of farm animal proteomics, and fewer still with expertise to apply state-of-the-art proteomic techniques. Possible explanations for this deficit may include the ease and availability of alternative largedata generating systems, which offer more extensive datasets (e.g. transcriptomics), access to instrumentation and associated costs, unfamiliarity with proteomics as a research tool, a lack of large animal research funding, or the lack of strategic planning to enable its more widespread use. Data and metrics on funding that use proteomics to address research questions for farm animal proteomics are available from a database maintained by The National Institute of Food and Agriculture, United States Department of Agriculture (https://nifa.usda. gov/data\#). A limited number of funded applications refer to farm animal proteomics, and examples include research goals to assess muscle fiber types in beef [25], bovine reproductive performance [26], the identification of biomarkers related to porcine heat-stress and nutrition [27] and disease detection in farm animals [28].

Given the advancements in genome sequencing and respective annotation of farm animal genomes, proteomics should be encouraged to address important biological questions. However, its uptake and application to farm animal research requires a more unified strategy, to include funding mechanisms to enhance training, themed research conferences and easier access to core facilities. A model to which the United States of America could look to would be the recent EU COST Action FA1002 on Farm Animal Proteomics previously mentioned that included collaborations with U.S. researchers. As such, transatlantic domestic animal proteomics networking can advance and could be a way to develop this field to the benefit of both regions. Proteomics in domestic animals in the USA and the rest of North America is finally a well-established research tool that researchers use in specific areas and research projects. Possibly, some additional work must be done in order to make it broader and more accessible. This can further be accomplished through the establishment of collaborative links such as those previously mentioned.

\section{Domestic animal proteomics in Brazil and Latin America in recent years}

The growing demand to improve the animal production system's efficiency has steadily increased research on Latin America's animal health and production over the past ten years. The development of highperformance tools for genome studies was essential in this area, enabling new knowledge and opening horizons for further questions about the relationship between genotype and phenotype. Proteomics studies began to be carried out in this context, although several groups were already active in Latin America's proteomics research from the 1990s onwards [29].

Brazil leads Latin American countries in publications on proteomics research from animals. About 987 results were revealed when a search was conducted in the PubMed (http://www.ncbi.nlm.gov/pubmed) database using "Proteomics, animal, and Brazil" terms. Approximately $68 \%$ of the articles were published in the last five years and include for instance topics such as beef quality and muscle function [30,31]. Pioneering reports also involved the proteome characterization of venomous secretions [32]. However, proteomic studies on animal health and production are still recent, with publications starting from 2012. In the São Paulo state, there are currently 109 projects in progress with a proteomic approach, supported by the São Paulo Research Foundation (FAPESP). Furthermore, a new multi-user equipment program funded by FAPESP has been remarkably successful at facilitating the development of proteomics research since it has provided the rational availability of the latest generation of equipment to researchers at the national and international levels.

Although several advances have been made in the field of proteomics with the assembly of well-equipped laboratories and trained teams, especially in some Latin American countries, such as Brazil, Mexico, Argentina, and Chile, collaborations are still the cornerstones of research in this area. Many laboratories are still focused on sample preparation and fractionation, requiring partners to analyze protein identification and perform bioinformatics analysis [33]. This is perhaps the most significant challenge for the region. The way it evolves depends largely on public and private funding for science and on how the regions' governments consider this a priority. Another important issue is a general lack of formal integration structures and programs at the regional level that still need be defined and established in these regions. Nevertheless, Latin America is an emerging area with great potential to be explored in domestic animal proteomics. It is extremely promising to apply proteomics in these countries that lead in the supply of products of animal origin, especially with the variety of such products and environmental conditions encountered. However, one of the most significant challenges is the scarcity of protein databases specifically aimed at the animal species from the region, such as Bos indicus for instance or for a variety of exotic animals that exist only in these countries. Finally, with an increase in funding support, animal scientists' training in proteomics and greater access to MS platforms still need to be achieved.

\section{Domestic animal proteomics in New Zealand and Australia in recent years}

The application of proteomics to domestic animal production in Australia and New Zealand has mainly been focused on the area of meat, milk and wool, most generally funded by government or industryspecific organizations such as Beef + Lamb New Zealand, the Wool Research Organization of New Zealand or Australian Wool Innovation. In wool, the focus has been on locating markers for the main quality traits of interest to farmers, fiber or staple strength and curvature, as these offer the best market returns [34]. Earlier this century, onedimensional electrophoresis was employed to characterize protein differences in wool between two Romney breeding lines of high and low tenacity wool staples, though it proved to be unsuccessful. From here, there was a progression to two-dimensional gel electrophoresis, visualizing the proteins with conventional stains, followed by quantitation by 2-DE gel analysis software [35,36]. This was initially applied to the examination of breeds at extreme ends of the curvature spectrum [37]. However, studying mutant sheep with radically different fiber morphologies [38] achieved more success. Over the last 10 years there has also been a move away from the 2-DE gel approach to that of MS, the use of iTRAQ labelling being used to examine the effect of feed restriction on wool fiber quality parameters, morphology and protein composition [39]. More recently, iTRAQ and label-free quantitation have been used to quantitate relative amounts of keratins between different breeds $[4,40]$.

In the case of meat producing farm animals some of the current efforts in New Zealand and Australia have been in developing an in-depth characterization of the proteome of specific cuts of meat using a shotgun 
proteomic evaluation and bioinformatic analysis. The use of MALDITOF/TOF MS has also been applied to study the effect of seasonal weight loss on the proteome of Damara, Dorper and Merino in Australia [41,42]. Proteomics is also being used in Australia to study paratuberculosis (Johne's disease) [43]. In this case, surface enhanced laser desorption ionization time-of-flight mass spectrometry (SELDI-TOF MS) is being performed to identify candidate biomarkers from sheep serum and then to monitor protein profile changes over time during an experimental infection trial.

With milk, there is an increasing interest in milk from species other than cows in New Zealand and here efforts are being directed into a more in-depth comparison of the sheep milk whey proteome in comparison to that of the cow [44]. The particular approach used was a mixture of an in-gel digest of 1D PAGE separation or an in-solution digest followed by OFFGEL isoelectric focusing, with the peptide fractions subsequently analyzed by LC-MS/MS [44].

Overall, it can be said that in Australia and New Zealand, similarly to the previously reported case of Latin America, research projects involving domestic animal proteomics have an emphasis on livestock production related topics and that the field appears to be well developed and supported at the public and private levels. Furthermore, in these two countries, researchers are well integrated and the links between proteomics platforms and field researchers is fully functional and leading to state-of-the-art research publications and projects of interest to the specific conditions of this geographical area.

\section{Domestic animal proteomics in Israel in recent years}

The use of proteomic analysis in domestic animal research in Israel has emerged during the last five years, and several studies have utilized this technique to gain in-depth information of the proteome profile of different tissues as part of comprehensive physiological experiments. To the best of our knowledge, the first proteomic analysis conducted in domestic animals in Israel was from the Volcani Center which revealed the proteome of subcutaneous adipose tissue in dairy cows and compared insulin resistant to insulin sensitive adipose tissue [45]. This was followed by proteomic analyses of subcutaneous adipose tissue from heat stressed transition dairy cows [46] or cows differing in the degree of metabolic stress [47]. Other proteomic studies in dairy cows have examined components of the reproductive tract, establishing the proteome of bovine follicular fluids from pre-ovulatory follicles of repeat breeder cows [48], or the proteome of oocytes exposed to phthalates [49] and of spermatozoa exposed to mycotoxin [50]. In chicken, only one collaborative study between Israel and Sweden examined the proteome of visceral adipose tissue from layers vs. broilers [51]. In addition, collaborations with research groups from the USA in which proteomics was performed and analyzed by the Israeli partner, examining liver [52] or adipose tissue [53] from dairy cows, are a good example of international cooperation that promotes proteomics research in domestic animals.

The proteomics studies conducted in Israel were funded by: a) German-Israel Foundation (GIF) young-scientist grant [46]; b) Israeli Dairy Council and Israel Science Foundation [47]; c) Israeli Academy of Science and Chief Scientist of the Israeli Minister of Agriculture [51]; d) the Environmental and Health fund of the Hebrew University [49]. Others have not received any specific funding [45,48,50,52,53]. It can thus be suggested that the very limited number of proteomic studies conducted in Israel can be mainly attributed to the difficulty to obtain research grants that support proteomics analyses. This, together with the high cost of outsourcing LC-MS/MS in the few available research facilities in Israel (such as the de Botton Institute for Protein Profiling, the Nancy and Stephen Grand Israel National Center for Personalized Medicine, the Weizmann Institute of Science, Rehovot; the Smoler Proteomics Center at the Technion, Haifa; and the Hebrew University, Jerusalem) pose additional difficulties to Israeli researchers working in the field. More research proposals that utilize proteomics as a main component of the research should be submitted to both national and international funding bodies. These could include for example, the Biotechnology in Agriculture section of the Chief Scientist of the Israeli Minister of Agriculture Fund, the Partnership on Research and Innovation in the Mediterranean Area (PRIMA) Fund and the United States Israel Binational Agricultural Research and Development Fund (BARD). This would surely increase the awareness and possibility to conduct proteomics in domestic animal research in Israel.

Nevertheless, Israeli proteomic studies have provided unique insights on the physiology of the examined tissues and revealed important canonical pathways as well as identifying proteins for the first time that are worthy of additional research, primarily in dairy cows. The amount of novel data obtained from proteomic analyses proves that it is a vital research tool in domestic animal research in Israel, and hopefully local and international grants will provide more opportunities for such research in the future.

\section{Domestic animal Proteomics in India in recent years}

India is a very diverse country with 15 agro climatic zones which have given rise to habitation of the highest number of domestic animals in the world ( $>500$ million) belonging to myriad species and breeds. Various breeds from different species include cattle (50), buffalo (17), goat (34), sheep (44), poultry (18), pig (10), camel (9), equine (7), yak, mithun (Bos frontalis), and chicken (19). Added to this is a large number of non-descript or uncharacterized breeds of animals. There is demand for development of high yielding and disease resistant livestock and agriculture products to meet the need for food of animal origin in the country. Research on proteomics in domestic animals in India started at a slow pace with a few isolated labs working in this area, but this has subsequently gained momentum, especially in the last decade. The main research focus has been on a few selected strains of disease-causing pathogens in domestic animals, as well as on animal production and reproduction with an aim to discover biomarkers. Animal science in India comes under the aegis of Indian Council of Agricultural Research (ICAR) and State Agriculture University system. With funding support from National Agriculture Innovation Project (NIAP) funded by ICAR, research on Animal Proteomics started in 2008. ICAR-National Dairy Research Institute (ICAR-NDRI), Karnal, India was supported by establishing proteomics infrastructure such as a 2-DE proteomics facility and an MS facility although similar facilities existed at the ICAR-Indian Agriculture Research Institute (ICAR-IARI), New Delhi, for crop proteomics. The establishment of this facility encouraged many young investigators to take up advanced research in animal proteomics.

Subsequently, various research groups throughout the country initiated proteomic research in domestic animals. For instance, a study on the proteome of Trypanosoma evansi (160 proteins) during infection in rodents that generally causes the disease 'Surra' both in rodents and in large animals such as camels, donkeys and equines and has ability to infect humans was conducted in Bangalore [54]. Another research group from Gwalior [55] used a 2-DE and MS approach to identify selected 48 exoproteomes from Clostridium perfringens (a bacterial pathogen responsible for various diseases in animals and humans) and their possible virulence. Mastitis is a major threat to animal productivity as it leads to immense economic losses for farmers. Recently, a group based in Karnal participated in a study [56] that identified major changes in the abundance levels of protein signatures (90 differentially abundant proteins) in milk during sub-clinical and clinical mastitis. The biomarker potential of these proteins should be explored further for the diagnosis of sub-clinical mastitis. Domestic animal proteomics has also been applied to animal production systems related to different aspects of lactation. These included the study of lactating mammary epithelial cells in cattle and water buffalo $[57,58]$, bovine milk proteome characterization and differentiation between breeds $[59,60]$ or the establishment of protein biomarkers for early pregnancy diagnosis [61] estrus detection [62], male fertility $[63,64]$. 
In conclusion, clinical proteomics in animals is producing remarkable productive outcomes for Indian proteomics researchers employing state-of-the-art laboratory and analytical methodologies. All these will benefit the proteomics community in the long term. However, these efforts are not enough for the benefit of the vast Indian domestic animal population. Despite some success stories, India is still some distance away from the successful translation of laboratory findings into clinical practice. India needs directed, supported plans to develop translational research through techno scientific mega projects in domestic animal proteomics. Collaboration between proteomics scientists and veterinary clinicians with adequate research facilities will expedite the accomplishment of well-designed multi-institutional and multi-centric investigations pointed at approaching the appropriate animal-based problems, evaluating disease outcomes and their validity.

\section{Domestic animal proteomics in China in recent years}

In the last decade, proteomics of domestic animals has attracted increasing attention in China. The information obtained from proteome levels is very helpful in exploring the proteins of interest and their physiological significance and this has been done in numerous fields of research in China. Given to the diversity of genetic resources and production of domestic animals in China, we will subsequently focus on the proteomic analysis of domestic dairy animals and their milk as an example.

In addition to Holstein dairy cows, buffaloes, yaks, goats, sheep, camels, horses, and donkeys are also considered minor dairy animals in China. They serve as an important source of nutrients including milk and meat and provide other economic benefits in various parts of China. Most proteomics studies of dairy animals in China have focused on Holstein dairy cows. Specifically, the effects of diet [65] or heat stress [66] on production performance and health status. In dairy goats, studied aspects included the effects of a high-grain diet on the hepatic and ruminal tissues [67,68], whereas in other dairy animals, most studies have focused on reproductive performance, for instance in buffaloes [69]; yaks [70]; sheep [71] and Bactrian camels [72].

From all these studies, it may be interesting to highlight one dedicated to casein and whey that are the two main milk protein fractions. Indeed, casein and whey account for respectively $80 \%$ and $20 \%$ of total proteins in ruminant milk while in non-ruminant milk, such as that from horses and humans, they account for $55 \%$ and $45 \%$ of total proteins. The proportions of casein and whey proteins in milk vary during lactation. The milk fat global membrane (MFGM) is another important component of milk protein and accounts for $1 \%$ of total proteins. Interestingly, the proteomics analysis of milk from minor dairy animals has attracted attention in China. The temporal proteomes of whey and their changes with the lactation stage and parity were characterized in Holstein dairy cows according to milk protein fractions. The relative abundances of several proteins, such as early lactation protein and syntenin, were associated with specific stages of the lactation cycle, and hemoglobin, $\beta$-lactoglobulin, and apolipoprotein E corresponded to the parity of Holstein dairy cows [73]. Another interesting research topic has been different comparative studies on the milk proteomes of different breeds of dairy animals that included for instance the comparison between water buffalo breeds [74].

Overall, China is one of the countries that is advancing rapidly in the use of domestic animal proteomics with a considerable number of research projects using this tool. It has benefited from a growing number of research facilities being established over the last few years and a scientific community with substantial growth. Projects have been selected for state-based funding and proteomics platforms established, and high-quality scientific literature is currently being produced. The studies mentioned above on the use of proteomics to address milk production and dairy specific issues are clear examples within this important area of domestic animal proteomics, currently being undertaken in China by local researchers. Such output could be improved through more integrated research relations with other countries.

\section{Domestic animal proteomics in Europe in recent years: North and South}

In Europe, animal production systems are conditioned by factors such as climate conditions, orography, economy and consumer preferences. There are not so many differences in the way Northern European (i.e. Denmark, Estonia, Finland, Ireland, Latvia, Norway, Sweden or the United Kingdom) and Southern European (i.e. Albania, Croatia, Greece, Italy, Portugal, Slovenia or Spain) countries raise dairy and beef cattle, pigs and poultry. However, other domestic animal species are managed differently in Northern Europe when compared to Southern Europe, or are of particular interest in specific regions of Europe. For instance, while meat sheep breeds are raised throughout Europe, in Northern Europe (e.g. Ireland) lambs are slaughtered at heavier weights compared to those in Southern Europe (e.g. Greece, Italy or Spain). In contrast, dairy sheep and dairy goats are mostly raised in Southern Europe, especially in Greece, Italy, Spain and Portugal. In addition, there are some domestic animal species that are produced only in specific countries such as Italy, where horses are bred for meat production and buffalos for milk production. Finally there are several countries like France that have regions with production systems closer to both of Northern and Southern Europe. Furthermore and as mentioned, some domestic animal species are relevant in certain parts of Europe while being marginal in others (e.g. dairy goats in Southern Europe and Northern Europe, respectively). Regarding aquaculture, several differences also exist, namely regarding the species farmed. For instance in Northern European countries like Norway or the United Kingdom, salmon is the leading species, whereas in Southern Europe, in countries like Italy or Greece seabass and gilthead seabream are the most important species. This fact has also influenced the focus European countries have made on the different research fields in animal science and this has been reflected by the different number of studies and publications.

To illustrate the above differences, and using web of science, we made an analysis on the bibliographic entries in the 2010-2020 period for countries that are representative of the Northern Europe production systems and countries that are representative of Southern Europe production systems. The former are Denmark, Estonia, Finland, Ireland, Latvia, Norway, Sweden and the United Kingdom, whereas the latter are Albania, Croatia, Greece, Italy, Portugal, Slovenia or Spain. We have purposely not included countries in Central Europe like Germany or Austria or countries like France that have both contexts. Indeed, and in our perspective they do not fall in either of the categories. The results are depicted in Fig. 1. They show, for the same species, a similar number of publications for Northern and Southern Europe in species that are well represented in both regions (cattle, sheep or pigs), whereas for species that are very specific to Southern Europe such as goats and buffalo, the numbers are several fold higher in Southern Europe. Over the last decade, the use of proteomics has of course exponentially increased worldwide [75]. Proteomics has provided complementary information to the well-established biochemical procedures used in animal science $[76,77]$. Some of the main negative aspects affecting the exponential development and use of several proteomics techniques are the high cost of the required infrastructure as well as the complexity of the data obtained when different approaches are combined [15]. In order to mitigate the above-mentioned aspects, the European Union has developed diverse programs aiming to provide access to proteomics infrastructure across Europe (i.e. PRIME-XS and EPIC-XS programs) and to promote collaboration among European research groups using proteomics in animal science (e.g COST action in Farm Animal Proteomics; FA 1002). The promotion of collaboration and access to proteomics facilities among different European countries justifies such a high number of publications in the field, being similar in both Southern and Northern European countries. In the near future, development of even more sensitive and accurate proteomics techniques will provide very useful tools 


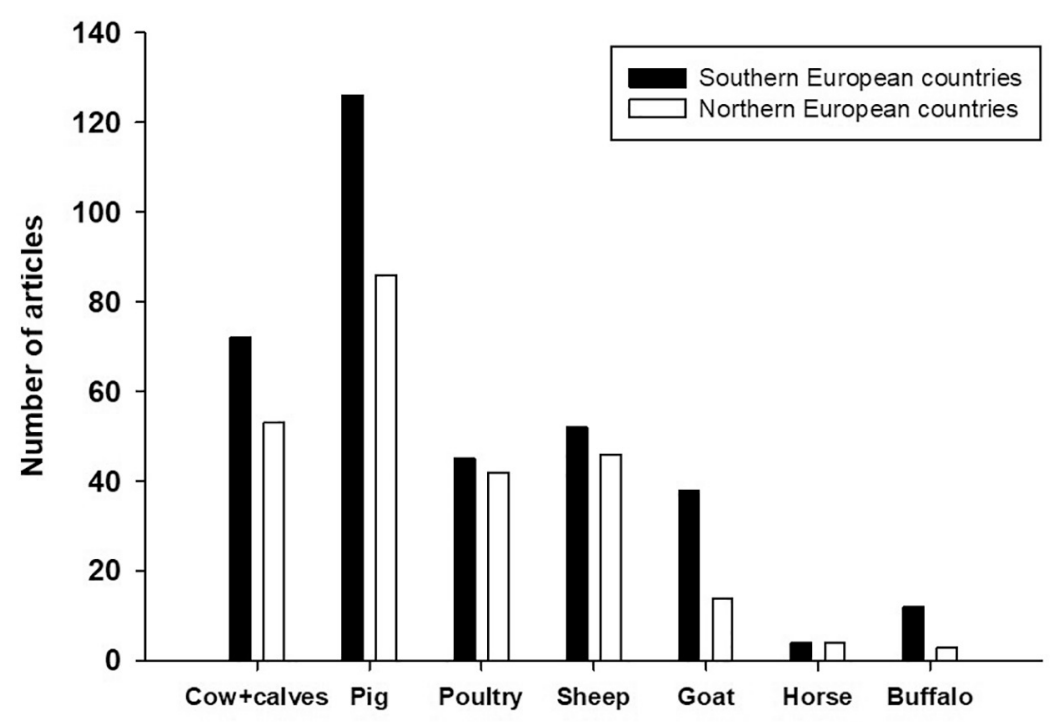

Proteomics studies performed in the different domestic animal species

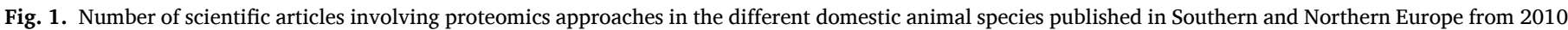
to 2020. Source: Web of Science.

that could be used in farm animals to assess not only diverse aspects of animal health, performance and welfare, but also several aspects related to their products such as milk and meat composition $[78,79]$. To do so, collaboration between European Countries and continued access to funding and infrastucture programs will be of the utmost importance.

\section{Domestic animal proteomics in Europe in recent years: East} and West

Proteomics is also an emerging field in veterinary medicine and animal science in Eastern Europe. As elsewhere, its limitations are the lack of available protein sequences from different animal species in the databases and information on the relevance of some detected proteins. The proteomic revolution started in Western countries. The political situation in Eastern Europe after the Second World War hindered its scientific development, but after the fall of the iron curtain, it began to make up ground. Since 2006, Central and Eastern European countries have formed the Central and Eastern European Proteomic Conference
(CEEPC), which aims to facilitate the exchange of knowledge and experience between countries [80]. In the field of domestic animal proteomics, Poland, Slovakia, and Croatia are producing the highest number of research papers with an impact among the countries of Eastern Europe. Since access to innovative equipment and expertise for proteome analysis is limited in Eastern Europe, collaboration with centers of proteomics and education of young researchers abroad is filling the gap until such facilities and know-how are readily available in the region. The COST Action on Farm Animal Proteomics (FA1002) is an excellent example. It was aimed to exchange experience and bridge the gap between the East and West [15]. The European Proteomics Infrastructure Consortium project (EPIC-XS, https://epic-Xs.eu) provides scientists with the option to access equipment in different laboratories throughout Europe for their proteomics research needs and to accelerate development of the field, including in Eastern countries.

In Eastern European countries, farm animal proteomics will have a high priority as these countries' economy is firmly connected to animal production. Therefore, proteomics research to monitor for factors

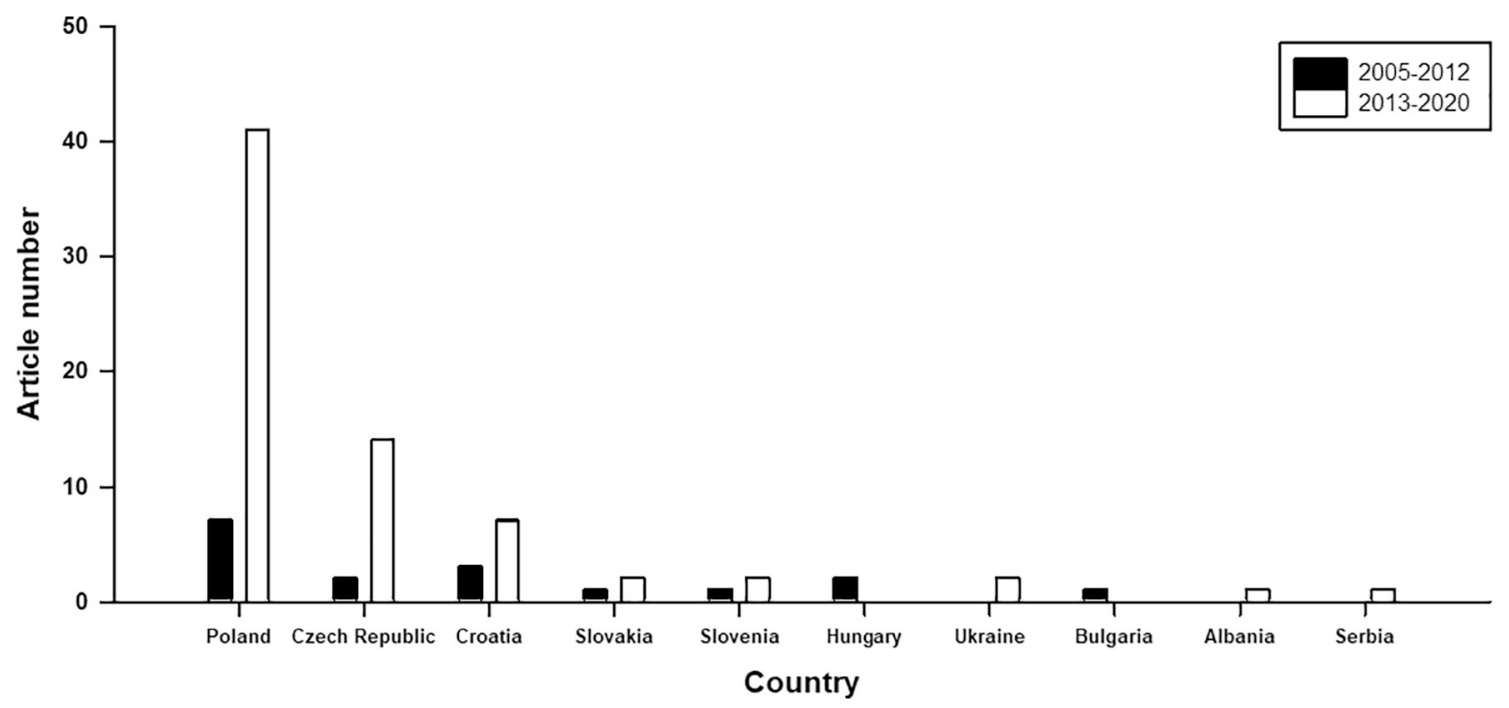

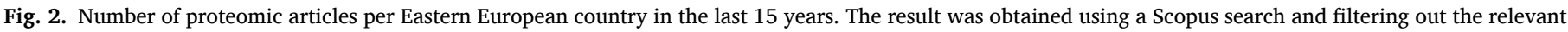
articles addressing issues in farm animal proteomics. An article was allocated to a country if at least one of the authors was from that country. 
relevant to animal health, fertility, welfare, and yield is a hot topic also in Eastern European countries (Fig. 2). To increase the accuracy of diagnostic tests in farm animals there is a trend to switch from a singleparameter biomarker to a multi-marker proteomics-based approach. Additionally, also in Eastern Europe, proteomics is extensively used in the fields of safety assessment and quality control of animal products, as well as for the investigation of pathological mechanisms of various pathogens $[15,81]$.

It is likely that the scientific output on domestic animal proteomics will increase specifically in Eastern Europe countries as will specific funding for mass spectrometry and other instrumentation. However, collaboration with other countries in Europe is of utmost importance for these countries in order to further develop the field and science as a whole.

\section{Initiatives towards the development of domestic animal proteomics}

10.1. Initiatives towards the development of proteomics supporting domestic animal proteomics: the PRIME-XS and EPIC-XS infrastructure access as case studies

Omics technologies initiated a new era in biological research. Using these new technologies, researchers are able to obtain a more holistic perspective of molecular systems and a better understanding of complex biological processes. Nevertheless, the technology is cost intensive; not only the instrumentation but also interpretation of the data requires expert knowledge and financial resources. In order to enable a costeffective wider usage of the omics technologies national and international research initiatives have been created to facilitate the access to omics technologies. PRIME-XS (Proteomics research infrastructure maximizing knowledge exchange and access) [82], was established in 2011 and it was one of the first European wide initiatives for proteomics research. Twelve distinct centers from nine countries build a strong joint research collaboration, developing new methods and computational tools and granting access to their proteomics infrastructure. That open access to cutting-edge proteomics infrastructures was a very new and a highly appreciated opportunity for many research groups all over Europe. Over the four years of the PRIME-XS program, 145 projects have been submitted and 122 projects executed. The positive evaluated projects were submitted from 23 European countries and researchers could visit the access sites to be directly involved in data acquisition and data analysis processes. A number of fruitful scientific partnerships have been established during that time and many young researchers were motivated to use omics technologies.

The majority of the projects were submitted from biomedical research fields, but it was very encouraging to see that groups from applied research with a focus on agricultural production, oenology, food safety or veterinary medicine obtained access to state-of-the-art proteomics technologies. However, only five projects of the 122 supported projects came from the these fields. Two projects investigated very important topics in meat production, which were seasonal weight loss problems in sheep [41], and meat quality markers in calves [8]. The latter study showed how proteome analysis of meat could provide molecular markers related to the production conditions. Calves that were imbedded in the more traditional meat production system with a discontinuous growth showed significantly higher levels of myosin binding protein $\mathrm{H}$ in their longissimus thoracis muscle. This example showed the great importance of molecular analysis in the meat production industry and that the results can be used to establish quality markers for meat production and animal welfare as well. It has to be noted that the result was generated in an explorative experimental design with moderate sample numbers. Therefore, verification studies in larger cohorts will have to show the robustness of the predicted molecular signature. Some of the small collaborative projects that were initiated during the PRIME-XS program have been continued successfully even after the program stopped.

In 2019, four years after the PRIME-XS project had finished, a new European Proteomics Infrastructure Consortium was funded by the EU Horizon 2020 program. The new program, EPIC-XS (www.epic-xs.eu), is a consortium of 18 research institutions from 16 different countries placed all over Europe and 11 institutions providing access to their cutting-edge proteomics facilities. The consortium has the aim to develop novel approaches for computational and structural proteomics, analysis of higher-order proteome organization, multi-omics integration and translational/clinical proteomics. The novel approaches are made accessible for the wider research community through the 11 access sites. During the first 2 years of the new EPIC-XS project 131 projects have already been submitted from 23 different countries. The very high project submission rate underlines the wide acceptance and the strong need of the research community to access high-end proteomics infrastructure. This is as well reflected in the domestic animal research field where five project applications have been positively evaluated and is a fantastic start of the new EPIC-XS program although applied research fields especially in the area of livestock and farm animal research are a minority group in the EPIC-XS user community. However, there is a strong effort being undertaken that more and more research groups from applied sciences have access to proteomics technologies. The results from the PRIME-XS program have shown the great potential of complex proteome analysis in livestock and farm animal research. Overall, it could be suggested that an EPIC-XS project specifically oriented to plant and animal research (in the framework of agricultural research) could be a way of rendering this technology more readily available to this specific research niche.

10.2. Initiatives towards the development of domestic animal proteomics: the buildup of the ERA-Chair project proteomics laboratory at the University of Zagreb as a case study

The European Commission announced during the last year of the 7th Framework Program an ERA-Chairs Pilot call to help close the research and innovation divide in Europe. The objective of the ERA Chair Initiative was to support universities and other research organizations located in convergence regions with a strong research capacity building profile, to significantly improve their performance in competitive research funding under the direction of outstanding researchers. ERA Chair projects are focused on carrying out structural changes in institutions that have the potential to improve their research innovation activities and achievement of excellence through the transparent selection of outstanding scientists, ERA-Chair holder who, in accordance with the strategic plan of the institution, ensure the implementation of the European Research Area priorities.

In order to conduct structural changes in veterinary medicine, to make a step towards the European environment and collaboration in European projects, scientists at the Faculty of Veterinary Medicine of the University of Zagreb (FVM) gladly participated in the ERA Chair initiative and specifically aimed at fostering structural changes and synergies between cohesion and research funding. Ultimately, it aimed to raise research quality in the application of molecular technologies to international levels of excellence. The project "Upgrading the research performance in molecular medicine at the Faculty of Veterinary Medicine University of Zagreb" (VetMedZg) aimed to reinforce research performance of FVM through enhancing its capacities in molecular veterinary medicine, by attracting outstanding experienced researchers and transfer of knowledge and research potential. Specific objectives of the project were to upgrade and develop capacities for research and research performance especially in post-genomic technologies (proteomics and metabolomics), comparative tumor analysis, and wildlife research.

To realize the overall strategy to full research, growth and innovation potential, along with the competitiveness of the FVM and generally veterinary sciences in Croatia, the VetMedZg project was divided into 
seven work packages. There was a total of 11 researchers and nonresearch staff employed by the project. Within the five years of project implementation, 8 project workshops with more than 60 invited foreign speakers were organized, with more than 40 international training courses, conferences, and seminars undertaken, all of which enhanced understanding of animal proteomics in south-east Europe. Project meetings with FVM and collaborating researchers created more than 60 published papers disseminating the results gained from the project's research. Through the years, the ERA Chair team and their associates have applied for more than 20 international and national projects, and three of those projects have been granted and are in implementation by FVM. With the help of ERA Chair team and project associates, FVM has established a productive cooperation with over 15 different institutions abroad and hosted 11 international students. In addition, FVM established a laboratory for proteomics as a core -omics facility at the FVM and broader region with state-of-the-art nanoLC and UHPLC MS/MS instruments, along with further instruments for proteomics and metabolomics research.

The FVM proteomics laboratory has therefore been at the center of collaborative investigations using advanced, novel proteomics technology in veterinary research. These activities resulted in several key points. These included the collaboration with partners in veterinary and animal science from throughout Europe, versatile methodology developed for quantitative proteomics and metabolomics across species, increased understanding of physiological and pathophysiological challenges. An overall aim has been to identify potential biomarkers of disease in animals by establishing a pipeline of sample preparation and MS (Q-Exactive Plus Orbitrap, Thermo Scientific) followed by statistical and bioinformatics analyses. Analysis of samples from cattle, sheep, pigs, chicken, dog, and cat as well as wild animals was performed and expertise developed in analyzing plasma [83], saliva [84], cerebrospinal fluid [85] and muscle [86] from different animal species.

By upgrading its research performance and excellence, FVM has improved performance in competitive research funding, prevented a brain drain of local talent, enhanced its competitiveness and visibility in the broader region and become an internationally recognized partner. By realization of the project, FVM has become one of the leading institution for research in molecular veterinary medicine not only in Croatia but also in southeast Europe.

\subsection{Initiatives towards the development of domestic animal proteomics: the Marie Curie MANNA PhD program and grant as a case study}

The European Joint Doctorate in Molecular Animal Nutrition (MANNA, www.phd4manna.eu, 2018-2022) is an EU funded initiative to provide Early Stage Researchers with a $\mathrm{PhD}$ double degree, based on Omics technologies applied to animal nutrition, from two of the partner academic institutes. MANNA is a unique initiative combining transcriptomics, microbiomics, metabolomics and proteomics to provide a system biology approach as comprehensive as possible, of the impact of innovative feeding regimens on livestock of three species, dairy cows, pigs and chicken, with selected immunomodulatory diets.

MANNA was born following the successful EU COST Action on Farm Animal Proteomics FA1002 that brought together experts in the field of proteomics applied to animals. The MANNA program is split into several sub-projects, each linked to a $\mathrm{PhD}$ student. Proteomics techniques are included in each of the individual sub-projects; with the targets varying from plasma to tissues and including sorted cellular population and nano-sized cellular particles.

As examples of the range of topics being investigated, in one of the projects, pigs fed in experimentally controlled conditions with diets enriched with PUFA and glucuronic acid, multiple sample types such as plasma, milk, muscle and intestinal contents are being collected and assessed by different Omics technologies. In another project, chicken fed with dietary supplements, comprising cucumber and citrus-based extracts the effects of lipopolysaccharide on plasma proteome and metabolome are being assessed. The dynamics of protein synthesis are also being investigated in the same chicken model but including treatment with heavy water, a stable isotope to allow determination of protein fractional synthesis rates. In other studies, sorted cells, such as fractionated white blood cells, or continuous intestinal cell lines, are incubated with the same dietary supplements and subsequently characterized for their proteome. Subcellular components, such as exosomes, after purification are being investigated, in order to provide insights into the proteomic basis of molecular communication between cells. Proteomics results are then integrated within a systems biology approach with data from transcriptomics, genomics, metabolomics and phenotypic data after developing a bioinformatics platform to generate indexes to measure and predict productive performance.

The MANNA project is currently training a cohort of animal scientists who are familiar with and adept at manipulating the intricacies of proteomics and other omics which will enable the essential applications of this advanced technology in animal sciences in the future.

\subsection{Initiatives towards the development of domestic animal proteomics:} Aquaculture and technology export: the Thai case study

In line with the increase of global fisheries, Thailand's aquaculture production, in 2016, reached more than 0.9 million tons, with farmed shrimps accounting for an estimated $40 \%$, fish $38 \%$ and mollusks $22 \%$ [87]. Of the 18 aquatic families farmed in Thailand, Nile Tilapia is the primary fish species, contributing to $15 \%$ of the overall and $38 \%$ of the freshwater aquaculture production. The number of freshwater aquaculture farms increased significantly from 131,000 in 1995 to more than 540,000 farms in 2015 [87]. Most of these farms are still small/family type productions that, due to the rising prices of fishery products, have changed their type of business, from rice production to aquaculture.

The need to modernize the aquaculture industry in Thailand, introducing new technologies and state-of-the-art scientific knowledge, led to the collaboration of co-author Prof. Pedro Rodrigues from the University of the Algarve (Portugal) with Prof. Surintorn Boonanuntanasarn from the Institute of Agricultural Technology at the Suranaree University of Technology, Thailand in 2017. As the leader of the proteomics division of the Aquaculture research group at Centro of Marine Sciences (CCMAR) at the University of the Algarve, the former was contacted by Professor Boonanuntanasarn in 2016, inquiring about the possibility of a collaboration in the area of proteomics. As both researchers worked in the aquaculture area, they realized the capabilities of this technology and the Thai counterparts showed an interest in starting to use proteomics in their studies, also complement their genomics work. The use of proteomics in Thailand was very scarce and nonexistent in the field of aquaculture. Both researchers decided to start a collaboration and initially organized at the Suranaree University of Technology one workshop and one ten-day course (in English) on proteomics and its applications to aquaculture. The course was financed by the European Asian Aquaculture Technology and Innovation Platform (Eurastip) with aquaculture Master's students, professors and Thailand aquaculture industry as the main target audience. The course was held over a 10-day period. Theoretical classes were focused on knowledge of what proteomics science is, the different technologies and strategies used with specific case studies from applications in Marine Sciences, more specifically in farmed fish. These classes also included seminars where students were gathered in a round table and discussed key scientific manuscripts and development of a small scientific project. Laboratory classes were focused on techniques such as sample preparation, 2-DE and MS. Visits to local aquaculture facilities took place as an important part of this course and allowed useful discussions with farmers, with technical advice and ideas for future research projects. A daily blog was produced with brief descriptions of the course activities, goals and pictures taken. Twenty-two master students, 4 professors and several sales personnel working for life sciences companies attended the course. The goals of this course, together with the ongoing collaboration between 
the Portuguese and Thai counterparts were designed to be the starting point to implement an annual subject of "proteomics in aquaculture" at the Institute of Agricultural Technology, Suranaree University of Technology, as part of the master's degree program.

This type of collaboration is extremely important, and Eurastip provided a structured basis within the aquaculture community for the joint Portugal and Thailand effort. Judging by the number of students visiting our laboratories as well as the three publications in peer-review journals resulting from this research on Nile tilapia nutrition and health [88-90], the collaboration was certainly a successful and prosperous one. However, like other bilateral initiatives such as one described between Portugal and Argentina [33], it was very dependent on the establishment of informal but solid research relations between scientists. Access to such bilateral and networking funding seems therefore to be again of key relevance.

\section{Future trends: Omics as a tool for animal and veterinary early-stage researchers}

Despite the limitations and pitfalls, the use of Omics has revolutionized animal and veterinary sciences. It has allowed the enhancement of selection programs for both crops and animals, enabling increased production, resistance against diseases and environmental sustainability [15]. Young researchers in the current and future generations need to embrace the technology while looking for multipurpose "swiss-armyknife-like" solutions to address such challenges. Additionally, these solutions have to be environmentally sustainable, easy to implement and economically viable. There are numerous examples of what will be needed in view of future climate changes. Animals need to adapt to increased temperatures that negatively affect production. The adaptation mechanisms of small ruminant goat breeds against weight loss during dry seasons has been extensively described using proteomics, transcriptomics and metabolomics [10,91,92]. Similarly, pig breeds answer differently to high temperature-humidity indexes, which has been supported by differential gene expression results [93]. The application of Omics has enabled the finding of pathways related to susceptibility and resilience to these stressors, which may help establish more resistant and productive strains. Modern animal production is highly dependent on crops imported from distant locations. Strategies can be designed to reduce the import costs and negative environmental impact. Using condensed tannins to increase dietary protein availability in low soybean meal lamb diets has shown promising results [9], whereas novel alternative feedstuffs such as microalgae are currently being tested [94]. Using proteomics to understand the physiological effects of such dietary alternatives has hence been successfully demonstrated [9,94].Recently, the use of phospho-proteomics has emerged as a new frontier in domestic animal research [95].

These are but a few examples of what Omics technologies allow. Their power lies in the high amount of information that can be obtained from a well-planned approach. The combination, of, for example, transcriptomics and proteomics, provides robust conclusions. It provides an insightful glimpse at molecular events taking place simultaneously at the various levels of the central dogma of molecular biology. In the future, making the experimental procedures cheaper and the development of technology that allows this multi-level interpretation is of paramount importance. Early stage researchers and PhD students will likely direct their future research efforts in such directions and using Omics will be a very valuable tool to address both fundamental and applied studies. Furthermore, researchers in their early careers are very motivated and primed to tackle such problems using state-of-the-art methodologies and tools such as Omics. Much more will need to be accomplished: improving selection programs in areas that are going through desertification (e.g. in the Mediterranean) preventing local food shortages and maintaining local populations [15] or establishing biomarkers to control the physiological state of wild game populations in susceptible ecosystems which will aid in the maintenance of hunter- gatherer communities and their way of life [96]. These entire ends link to a common point: only accumulation patterns of genes, transcripts, proteins and metabolites can effectively explain biological processes. To harness such information, the usefulness of Omics is undeniable.

Finally, the COVID-19 pandemic has created some severe disruptions to $\mathrm{PhD}$ programs. This has affected both classic $\mathrm{PhD}$ programs and those such as the MANNA project mentioned above, which incorporate enhanced mobility of PhD students. The way research is conducted and also the way findings are delivered to a scientific audience has been severely affected by the pandemic. Indeed, in the best case scenario the pandemic will have caused a 2-year long disruption to scientific activities. That is half or $2 / 3$ of the time of a standard $\mathrm{PhD}$ project. As such, novel ways of conducting research work and above all disseminate it, for instance through virtual congresses and workshops or the interchange of research results via collaboration will be an important way of minimizing the effects of COVID-19 for PhD students.

\section{Conclusions and future prospects}

Domestic animal proteome studies are an exciting and novel field. Certainly, it is a field that has specific and inherent difficulties. These include lack of access to specialized proteomics platforms and the funding difficulties given the high costs to equip and run such instrumentation. Additionally, there are other difficulties that are related to the technique and the subject of research itself, namely the difficulty in working with some samples or the lack of coverage of public protein databases, particularly in certain species.

There is also an important aspect related to the fundamental nature of most of the proteomics work done in the framework of domestic animal science described above. In fact, links to industry are frequently not the norm. As such, it is of the utmost relevance to bring commercial companies into the equation and establish partnerships in research. There are some examples, for instance regarding some of the previously mentioned references $[4,8,14]$. However, this aspect is, without doubt, improvable and would likely help proteomics in domestic animal research to achieve a broader scope and relevance.

Another important aspect where proteomics may play a pivotal role in the context of domestic animal research is related to the environment and sustainability. Indeed, and due to the pressing issue of climate change-induced challenges it is very important to focus research also on this context, complementing the traditional areas of animal science (nutrition, genetics, reproduction, health and others). Proteomics is particularly suitable to address this challenge as it is used much more frequently in environmental sciences than in animal and veterinary sciences. Applications could include for instance the use of alternative feedstuffs such as algae [94] or insect meal, monitoring ruminal fermentation manipulation through the animal diets [76] or contribute to a more sustainable extensive production system highlighting the benefits also for product quality [8]. These, together with improvements towards the increase of animal welfare for instance in damaging behavior of pigs [93] or in cattle by characterizing heat stress effects $[52,53]$, are areas where the contributions of proteomics is crucial.

Despite the existing challenges and numerous areas of future research, it is clear that researchers working in domestic animal proteomics over the last 10 years have successfully overcome many difficulties and proteomics has since become a scientific tool of regular use in animal and veterinary sciences. It is important to notice that each country or region has dealt with such difficulties in different ways and according to the different means and possibilities available. Nevertheless, it is noteworthy to mention that to overcome such difficulties, international collaboration is a cornerstone resource. Indeed, international collaboration allows securing funds, building dedicated proteomics labs such as the facility in Zagreb, providing access to stateof-the-art proteomics platforms (PRIME-XS) or creating an international research network of scientists specialized in the field (COST action 
FA1002)

Overall, only an approach based on international collaboration makes it possible to further develop the field and address the numerous challenges that domestic animal research faces. Finally, international cooperation will ultimately allow the training of present-day $\mathrm{PhD}$ students who are likely to become, in the future, leading researchers in the field, bringing in turn much-needed novel skills, approaches and way of thinking that will be of utmost importance to the development of animal and veterinary sciences.

\section{Credit author statement}

All authors contributed equally to this manuscript.

\section{Data availability}

No data was used for the research described in the article.

\section{Acknowledgements}

Authors AM Almeida and DM Ribeiro acknowledge funding from the Science and Technology Foundation (Lisbon, Portugal) through LEAF Research Center (UID/AGR/04129/2020) and PhD grant SFRH/BD/ 143992/2019 attributed to DM Ribeiro. Author PM Rodrigues acknowledges the Eurastip Exchange program, the Science and Technology Foundation (Lisbon, Portugal) through project UID/Multi/04326/ 2020 and Mar2020 projects WELFISH (16-02-05-FMP-12, - Establishment of Welfare Biomarkers in farmed fish using a proteomics approach) and ALLYFISH (16-02-01-FMP-0014 - Development of a farmed fish with reduced allergenic potential). Authors Rongwei Han and Yongxin Yan acknowledge Dr. Shanshan Li from the College of Animal Sciences (Zhejiang University, China) for her suggestions for improvements on the section of the manuscript on Domestic Animal Proteomics in China. Author Mirele Poleti acknowledges research funding from the Conselho Nacional de Desenvolvimento Científico e Tecnológico (Brasília, DF, Brazil) reference CNPq 409186/2018-0 and a fellowship grant from CAPES Coordenação de Aperfeiçoamento de Pessoal de Nível Superior (Brasília, Brazil), finance code 001. Authors J Starič and JJ Hodnik acknowledge the support of research program Animal health, environment and food safety (P4-0092) of Veterinary Faculty, University of Ljubljana, funded by the Slovenian Research Agency (ARRS). EU is thanked for funding of COST action FA1002 Farm Animal Proteomics; European Commission FP7 VETMEDZG project (grant number 621394); European Regional Development Fund (Grant Agreement KK.01.1.1.04.0086) and Marie Sklodowska-Curie European Joint Doctorate MANNA project No 765423. Authors P Nanni, B Roschitzki and R Schlapbach acknowledge funding from the European Union's Horizon 2020 research and innovation program under grant agreement No 823839 (EPIC-XS).

\section{References}

[1] G. Paredi, S. Raboni, E. Bendixen, A.M. de Almeida, A. Mozzarelli, "Muscle to meat" molecular events and technological transformations: the proteomics insight, J. Proteomics 75 (2012) 4275-4289, https://doi.org/10.1016/j.jprot.2012.04.011.

[2] G. Paredi, M.A. Sentandreu, A. Mozzarelli, S. Fadda, K. Hollung, A.M. de Almeida, Muscle and meat: new horizons and applications for proteomics on a farm to fork perspective, J. Proteomics 88 (2013) 58-82, https://doi.org/10.1016/j. jprot.2013.01.029.

[3] I. Marcelino, A.M. de Almeida, M. Ventosa, L. Pruneau, D.F. Meyer, D. Martinez, T. Lefrançois, N. Vachiéry, A.V. Coelho, Tick-borne diseases in cattle: applications of proteomics to develop new generation vaccines, J. Proteomics 75 (2012) 4232-4250, https://doi.org/10.1016/j.jprot.2012.03.026.

[4] J. Plowman, A. Thomas, T. Perloiro, S. Clerens, A.M. De Almeida, Characterisation of white and black merino wools: a proteomics study, Animal 13 (2019) 659-665, https://doi.org/10.1017/S1751731118001647.

[5] P.M. Rodrigues, T.S. Silva, J. Dias, F. Jessen, PROTEOMICS in aquaculture: applications and trends, J. Proteomics 75 (2012) 4325-4345, https://doi.org/ 10.1016/j.jprot.2012.03.042.

[6] E. Ferlizza, A. Campos, A. Neagu, A. Cuoghi, E. Bellei, E. Monari, F. Dondi, A. M. Almeida, G. Isani, The effect of chronic kidney disease on the urine proteome in the domestic cat (Felis catus), Vet. J. 204 (2015) 73-81, https://doi.org/10.1016/j. tvil.2015.01.023.

[7] E. Ferlizza, G. Isani, F. Dondi, G. Andreani, K. Vasylyeva, E. Bellei, A.M. Almeida, M. Matzapetakis, Urinary proteome and metabolome in dogs (Canis lupus familiaris): the effect of chronic kidney disease, J. Proteomics 222 (2020) 103795, https://doi.org/10.1016/j.jprot.2020.103795.

[8] A.M. Almeida, P. Nanni, A.M. Ferreira, C. Fortes, J. Grossmann, R.J.B. Bessa, P. Costa, The longissimus thoracis muscle proteome in Alentejana bulls as affected by growth path, J. Proteomics 152 (2017) 206-215, https://doi.org/10.1016/j. jprot.2016.10.020.

[9] D.M. Ribeiro, S. Planchon, C.C. Leclercq, M.T.P. Dentinho, R.J.B. Bessa, J. SantosSilva, K. Paulos, E. Jerónimo, J. Renaut, A.M. Almeida, The effects of improving low dietary protein utilization on the proteome of lamb tissues, J. Proteomics 103798 (2020), https://doi.org/10.1016/j.jprot.2020.103798.

[10] L.E. Hernández-Castellano, A.M. Ferreira, P. Nanni, J. Grossmann, A. Argüello, J. Capote, G. Cai, J. Lippolis, N. Castro, A.M. de Almeida, The goat (Capra hircus) mammary gland secretory tissue proteome as influenced by weight loss: a study using label free proteomics, J. Proteomics 145 (2016) 60-69, https://doi.org/ 10.1016/j.jprot.2016.03.030.

[11] I. Miller, C. Rogel-Gaillard, D. Spina, L. Fontanesi, A. de Almeida, The rabbit as an experimental and production animal: from genomics to proteomics, Curr. Protein Pept. Sci. 15 (2014) 134-145, https://doi.org/10.2174/ 1389203715666140221115135.

[12] V.M.R. Pires, M.S. Madeira, A.A. Dowle, J. Thomas, A.M. Almeida, J.A.M. Prates, Increased intramuscular fat induced by reduced dietary protein in finishing pigs: effects on the longissimus lumborum muscle proteome, Mol. BioSyst. 12 (2016) 2447-2457, https://doi.org/10.1039/c6mb00213g.

[13] A.M. de Almeida, E. Bendixen, Pig proteomics: a review of a species in the crossroad between biomedical and food sciences, J. Proteomics 75 (2012) 4296-4314, https://doi.org/10.1016/j.jprot.2012.04.010.

[14] E.L. O'Reilly, R.J. Burchmore, N.H. Sparks, P.D. Eckersall, The effect of microbial challenge on the intestinal proteome of broiler chickens, Proteome Sci. 15 (2016) 10, https://doi.org/10.1186/s12953-017-0118-0.

[15] A.M. Almeida, A. Bassols, E. Bendixen, M. Bhide, F. Ceciliani, S. Cristobal, P. D. Eckersall, K. Hollung, F. Lisacek, G. Mazzucchelli, M. McLaughlin, I. Miller, J. E. Nally, J. Plowman, J. Renaut, P. Rodrigues, P. Roncada, J. Staric, R. Turk, Animal board invited review: advances in proteomics for animal and food sciences, Animal 9 (2014) 1-17, https://doi.org/10.1017/S1751731114002602.

[16] E. Gelpí, From large analogical instruments to small digital black boxes: 40 years of progress in mass spectrometry and its role in proteomics. Part I 1965-1984, J. Mass Spectrom. 43 (2008) 419-435, https://doi.org/10.1002/jms.1403.

[17] E. Gelpí, From large analogical instruments to small digital black boxes: 40 years of progress in mass spectrometry and its role in proteomics. Part II 1985-2000, J. Mass Spectrom. 44 (2009) 1137-1161, https://doi.org/10.1002/jms.1621.

[18] N.G. Anderson, N.L. Anderson, Twenty years of two-dimensional electrophoresis: past, present and future, Electrophoresis 17 (1996) 443-453, https://doi.org/ 10.1002/elps.1150170303.

[19] P. Picotti, R. Aebersold, Selected reaction monitoring-based proteomics: workflows, potential, pitfalls and future directions, Nat. Methods 9 (2012) 555-566, https://doi.org/10.1038/nmeth.2015.

[20] W. Cui, H.W. Rohrs, M.L. Gross, Top-down mass spectrometry: recent developments, applications and perspectives, Analyst 136 (2011) 3854, https:// doi.org/10.1039/c1an15286f.

[21] V. Marx, A dream of single-cell proteomics, Nat. Methods 16 (2019) 809-812, https://doi.org/10.1038/s41592-019-0540-6.

[22] P.D. Eckersall, A.M. de Almeida, I. Miller, Proteomics, a new tool for farm animal science, J. Proteomics 75 (2012) 4187-4189, https://doi.org/10.1016/j. jprot.2012.05.014.

[23] A.M. de Almeida, I. Miller, D. Eckersall, Proteomics in Domestic Animals: From Farm to Systems Biology, Springer International Publishing, Cham, 2018, https:// doi.org/10.1007/978-3-319-69682-9.

[24] J.D. Lippolis, E.J. Powell, T.A. Reinhardt, T.C. Thacker, E. Casas, Symposium review: omics in dairy and animal science-promise, potential, and pitfalls, J. Dairy Sci. 102 (2019) 4741-4754, https://doi.org/10.3168/jds.2018-15267.

[25] G.-D. Kim, H.-S. Yang, J.-Y. Jeong, Intramuscular variations of proteome and muscle fiber type distribution in semimembranosus and semitendinosus muscles associated with pork quality, Food Chem. 244 (2018) 143-152, https://doi.org/ 10.1016/j.foodchem.2017.10.046.

[26] M.H. Kamalludin, A. Garcia-Guerra, M.C. Wiltbank, B.W. Kirkpatrick, Proteomic analysis of follicular fluid in carriers and non-carriers of the trio allele for high ovulation rate in cattle, Reprod. Fertil. Dev. 30 (2018) 1643, https://doi.org/ $10.1071 / R D 17252$.

[27] S.M. Cruzen, S.C. Pearce, L.H. Baumgard, N.K. Gabler, E. Huff-Lonergan, S. M. Lonergan, Proteomic changes to the sarcoplasmic fraction of predominantly red or white muscle following acute heat stress, J. Proteomics 128 (2015) 141-153, https://doi.org/10.1016/j.jprot.2015.07.032.

[28] A.N. Rai, W.B. Epperson, B. Nanduri, Application of functional genomics for bovine respiratory disease diagnostics, Bioinform. Biol. Insights. 9 (2015) 13-23, https:// doi.org/10.4137/BBi.s30525.

[29] G. Padrón, G.B. Domont, Two decades of proteomics in Latin America: a personal view, J. Proteomics 107 (2014) 83-92, https://doi.org/10.1016/j. jprot.2014.03.045.

[30] M.D. Poleti, L.C.A. Regitano, G.H.M.F. Souza, A.S.M. Cesar, R.C. Simas, B. SilvaVignato, G.B. Oliveira, S.C.S. Andrade, L.C. Cameron, L.L. Coutinho, Longissimus dorsi muscle label-free quantitative proteomic reveals biological mechanisms 
associated with intramuscular fat deposition, J. Proteomics 179 (2018) 30-41, https://doi.org/10.1016/j.jprot.2018.02.028.

[31] M.D. Poleti, C.T. Moncau, B. Silva-Vignato, A.F. Rosa, A.R. Lobo, T.R. Cataldi, J. A. Negrão, S.L. Silva, J.P. Eler, J.C. de Carvalho Balieiro, Label-free quantitative proteomic analysis reveals muscle contraction and metabolism proteins linked to ultimate pH in bovine skeletal muscle, Meat Sci. 145 (2018) 209-219, https://doi. org/10.1016/j.meatsci.2018.06.041.

[32] A. Chapeaurouge, A. Silva, P. Carvalho, R.J.R. McCleary, C.M. Modahl, J. Perales, R.M. Kini, S.P. Mackessy, Proteomic deep mining the venom of the red-headed krait, Bungarus flaviceps, Toxins (Basel) 10 (2018) 1-19, https://doi.org/10.3390/ toxins10090373.

[33] S. Fadda, A.M. Almeida, Proteomics in Argentina - limitations and future perspectives: a special emphasis on meat proteomics, Proteomics. 15 (2015) 3676-3687, https://doi.org/10.1002/pmic.201500185.

[34] J.E. Plowman, S. Deb-Choudhury, S. Clerens, A. Thomas, C.D. Cornellison, J. M. Dyer, Unravelling the proteome of wool: towards markers of wool quality traits, J. Proteomics 75 (2012) 4315-4324, https://doi.org/10.1016/j.jprot.2012.03.027.

[35] L.M. Flanagan, J.E. Plowman, W.G. Bryson, The high sulphur proteins of wool: Towards an understanding of sheep breed diversity, Proteomics 2 (2002) 1240-1246, https://doi.org/10.1002/1615-9861.

[36] J.E. Plowman, L.M. Flanagan, L.N. Paton, A.C. Fitzgerald, N.I. Joyce, W.G. Bryson, The effect of oxidation or alkylation on the separation of wool keratin proteins by two-dimensional gel electrophoresis, Proteomics 3 (2003) 942-950, https://doi. org/10.1002/pmic.200300419.

[37] J.E. Plowman, L.N. Paton, W.G. Bryson, The differential expression of proteins in the cortical cells of wool and hair fibres, Exp. Dermatol. 16 (2007) 707-714, https://doi.org/10.1111/j.1600-0625.2007.00576.x.

[38] J.E. Plowman, D.P. Harland, D.R. Scobie, D. O'Connell, A. Thomas, P.H. Brorens, M. Richena, E. Meenken, A.J. Phillips, J.A. Vernon, S. Clerens, Differences between ultrastructure and protein composition in straight hair fibres, Zoology 133 (2019) 40-53, https://doi.org/10.1016/j.zool.2019.01.002.

[39] A.M. Almeida, J.E. Plowman, D.P. Harland, A. Thomas, T. Kilminster, T. Scanlon, J. Milton, J. Greeff, C. Oldham, S. Clerens, Influence of feed restriction on the woo proteome: a combined iTRAQ and fiber structural study, J. Proteomics 103 (2014) 170-177, https://doi.org/10.1016/j.jprot.2014.03.036.

[40] J.E. Plowman, D.P. Harland, A.M.O. Campos, S. Rocha e Silva, A. Thomas, J. A. Vernon, C. van Koten, C. Hefer, S. Clerens, A.M. de Almeida, The wool proteome and fibre characteristics of three distinct genetic ovine breeds from Portugal, J. Proteomics 225 (2020), https://doi.org/10.1016/j.jprot.2020.103853.

[41] A.M. Ferreira, J. Grossmann, C. Fortes, T. Kilminster, T. Scanlon, J. Milton, J. Greeff, C. Oldham, P. Nanni, A.M. Almeida, The sheep (Ovis aries) muscle proteome: decoding the mechanisms of tolerance to seasonal weight loss using label-free proteomics, J. Proteomics 161 (2017) 57-67, https://doi.org/10.1016/j. jprot.2017.03.020.

[42] B. Miller, N. Selevsek, J. Grossmann, T. Kilminster, T. Scanlon, M. Daniels, P. Nanni, J. Milton, C. Oldham, J. Greeff, A. Chapwanya, D. Bergfelt, A.M. de Almeida, Ovine liver proteome: assessing mechanisms of seasonal weight loss tolerance between merino and Damara sheep, J. Proteomics 191 (2019) 180-190, https://doi.org/10.1016/j.jprot.2018.02.018.

[43] L. Zhong, D. Taylor, D.J. Begg, R.J. Whittington, Biomarker discovery for ovine paratuberculosis (Johne's disease) by proteomic serum profiling, Comp. Immunol Microbiol. Infect. Dis. 34 (2011) 315-326, https://doi.org/10.1016/j. cimid.2011.03.001.

[44] M. Ha, M. Sabherwal, E. Duncan, S. Stevens, P. Stockwell, M. McConnell, A. El-Din Bekhit, A. Carne, In-depth characterization of sheep (Ovis aries) milk whey proteome and comparison with cow (Bos taurus), PLoS One 10 (2015), https://doi. org/10.1371/journal.pone.0139774.

[45] M. Zachut, Defining the adipose tissue proteome of dairy cows to reveal biomarkers related to Peripartum insulin resistance and metabolic status, J. Proteomics Res. 14 (2015) 2863-2871, https://doi.org/10.1021/acs.jproteome.5b00190.

[46] M. Zachut, G. Kra, L. Livshitz, Y. Portnick, S. Yakoby, G. Friedlander, Y. Levin Seasonal heat stress affects adipose tissue proteome toward enrichment of the Nrf2mediated oxidative stress response in late-pregnant dairy cows, J. Proteomics 158 (2017) 52-61, https://doi.org/10.1016/j.jprot.2017.02.011.

[47] M. Zachut, G. Kra, U. Moallem, L. Livshitz, Y. Levin, S. Udi, A. Nemirovski, J. Tam, Characterization of the endocannabinoid system in subcutaneous adipose tissue in periparturient dairy cows and its association to metabolic profiles, PLoS One 13 (2018) 1-22, https://doi.org/10.1371/journal.pone.0205996.

[48] M. Zachut, P. Sood, Y. Levin, U. Moallem, Proteomic analysis of preovulatory follicular fluid reveals differentially abundant proteins in less fertile dairy cows, J. Proteomics 139 (2016) 122-129, https://doi.org/10.1016/j.jprot.2016.03.027.

[49] D. Kalo, A. Vitorino Carvalho, C. Archilla, V. Duranthon, M. Moroldo, Y. Levin, M. Kupervaser, Y. Smith, Z. Roth, Mono(2-ethylhexyl)phthalate (MEHP)induces transcriptomic alterations in oocytes and their derived blastocysts, Toxicology. 421 (2019) 59-73, https://doi.org/10.1016/j.tox.2019.04.016.

[50] A. Komsky-Elbaz, D. Kalo, Z. Roth, Effect of aflatoxin B1 on bovine spermatozoa's proteome and embryo's transcriptome, Reproduction. 160 (2020) 709-723, https://doi.org/10.1530/REP-20-0286.

[51] S. Bornelöv, E. Seroussi, S. Yosefi, S. Benjamini, S. Miyara, M. Ruzal, M. Grabherr, N. Rafati, A.M. Molin, K. Pendavis, S.C. Burgess, L. Andersson, M. Friedman-Einat, Comparative omics and feeding manipulations in chicken indicate a shift of the endocrine role of visceral fat towards reproduction, BMC Genomics 19 (2018) 1-15, https://doi.org/10.1186/s12864-018-4675-0.

[52] A.L. Skibiel, M. Zachut, B.C. do Amaral, Y. Levin, G.E. Dahl, Liver proteomic analysis of postpartum Holstein cows exposed to heat stress or cooling conditions during the dry period, J. Dairy Sci. 101 (2018) 705-716, https://doi.org/10.3168/ jds.2017-13258.

[53] C.S. Takiya, S.R. Montgomery, L.K. Mamedova, G. Kra, N. Nemes-Navon, Y. Levin, S.D. Fleming, B.J. Bradford, M. Zachut, Proteomic analysis reveals greater abundance of complement and inflammatory proteins in subcutaneous adipose tissue from postpartum cows treated with sodium salicylate, J. Proteomics 204 (2019) 103399, https://doi.org/10.1016/j.jprot.2019.103399.

[54] N. Roy, R.K. Nageshan, R. Pallavi, H. Chakravarthy, S. Chandran, R. Kumar, A. K. Gupta, R.K. Singh, S.C. Yadav, U. Tatu, Proteomics of Trypanosoma evansi infection in rodents, PLoS One 5 (2010), https://doi.org/10.1371/journal. pone.0009796.

[55] N. Sengupta, S.I. Alam, B. Kumar, R.B. Kumar, V. Gautam, S. Kumar, L. Singh, Comparative proteomic analysis of extracellular proteins of Clostridium perfringens type a and type C strains, Infect. Immun. 78 (2010) 3957-3968, https://doi.org/ 10.1128/IAI.00374-10.

[56] S. Bathla, A. Sindhu, S. Kumar, S.K. Dubey, S. Pattnaik, P. Rawat, A. Chopra, A. Dang, J.K. Kaushik, A.K. Mohanty, Tandem Mass Tag (TMT)-based quantitative proteomics reveals potential targets associated with onset of Sub-clinical Mastitis in cows, Sci. Rep. 10 (2020) 1-10, https://doi.org/10.1038/s41598-020-66211-6.

[57] J. Janjanam, M. Jamwal, S. Singh, S. Kumar, A.K. Panigrahi, G. Hariprasad, M. K. Jena, V. Anand, S. Kumar, J.K. Kaushik, A.K. Dang, M. Mukesh, B.P. Mishra, A. Srinivasan, V.S. Reddy, A.K. Mohanty, Proteome analysis of functionally differentiated bovine (Bos indicus) mammary epithelial cells isolated from milk, Proteomics. 13 (2013) 3189-3204, https://doi.org/10.1002/pmic.201300031.

[58] S. Jaswal, V. Anand, S. Kumar, S. Bathla, A.K. Dang, J.K. Kaushik, A.K. Mohanty, In-depth proteome analysis of more than 12,500 proteins in buffalo mammary epithelial cell line identifies protein signatures for active proliferation and lactation, Sci. Rep. 10 (2020) 1-13, https://doi.org/10.1038/s41598-020-61521 1 .

[59] S.A. Bhat, S.M. Ahmad, E.M. Ibeagha-Awemu, M. Mobashir, M.A. Dar, P. T. Mumtaz, R.A. Shah, T.A. Dar, N. Shabir, H.F. Bhat, N.A. Ganai, Comparative milk proteome analysis of Kashmiri and Jersey cattle identifies differential expression of key proteins involved in immune system regulation and milk quality, BMC Genomics 21 (2020) 1-10, https://doi.org/10.1186/s12864-020-6574-4.

[60] A. Chopra, S.A. Ali, S. Bathla, P. Rawat, V. Vohra, S. Kumar, A.K. Mohanty, Highresolution mass spectrometer-based ultra-deep profile of milk whey proteome in Indian Zebu (Sahiwal) cattle, Front. Nutr. 7 (2020), https://doi.org/10.3389/ fnut.2020.00150.

[61] P. Rawat, S. Bathla, R. Baithalu, M.L. Yadav, S. Kumar, S.A. Ali, A. Tiwari, M. Lotfan, J. Naru, M. Jena, P. Behere, A.K. Balhara, R. Vashisth, I. Singh, A. Dang, J.K. Kaushik, T.K. Mohanty, A.K. Mohanty, Identification of potential protein biomarkers for early detection of pregnancy in cow urine using 2D DIGE and label free quantitation, Clin. Proteomics 13 (2016) 1-14, https://doi.org/10.1186/ s12014-016-9116-y.

[62] N.G. Shashikumar, R.K. Baithalu, S. Bathla, S.A. Ali, P. Rawat, A. Kumaresan, S. Kumar, B.R. Maharana, G. Singh, D.S. Puneeth Kumar, S.K. Singh, S.S. Lathwal, L. Jaiswal, T.K. Mohanty, A.K. Mohanty, Global proteomic analysis of water buffalo (Bubalus bubalis) saliva at different stages of estrous cycle using high throughput mass spectrometry, Theriogenology. 110 (2018) 52-60, https://doi.org/10.1016/j. theriogenology.2017.12.046.

[63] M.K. Muhammad Aslam, A. Kumaresan, S. Yadav, T.K. Mohanty, T.K. Datta, Comparative proteomic analysis of high- and low-fertile buffalo bull spermatozoa for identification of fertility-associated proteins, Reprod. Domest. Anim. 54 (2019) 786-794, https://doi.org/10.1111/rda.13426.

[64] K.P. Ramesha, P. Mol, U. Kannegundla, L.N. Thota, L. Gopalakrishnan, E. Rana, N. Azharuddin, K.K. Mangalaparthi, M. Kumar, G. Dey, A. Patil, K. Saravanan, S. K. Behera, S. Jeyakumar, A. Kumaresan, M.A. Kataktalware, T.S.K. Prasad, Deep proteome profiling of semen of Indian indigenous Malnad Gidda (Bos indicus) cattle, J. Proteomics Res. 19 (2020) 3364-3376, https://doi.org/10.1021/acs. jproteome.0c00237.

[65] W. Dai, Q. Wang, F. Zhao, J. Liu, H. Liu, Understanding the regulatory mechanisms of milk production using integrative transcriptomic and proteomic analyses: improving inefficient utilization of crop by-products as forage in dairy industry, BMC Genomics 19 (2018) 1-18, https://doi.org/10.1186/s12864-018-4808-5.

[66] L. Min, S. Zhao, H. Tian, X. Zhou, Y. Zhang, S. Li, H. Yang, N. Zheng, J. Wang, Metabolic responses and "omics" technologies for elucidating the effects of heat stress in dairy cows, Int. J. Biometeorol. 61 (2017) 1149-1158, https://doi.org/ 10.1007/s00484-016-1283-z.

[67] M. He, L. Li, H. Wang, S. Yan, Y. Zhang, Effects of high-grain diet with buffering agent on the hepatic metabolism in lactating goats, Front. Physiol. 10 (2019) 1-12, https://doi.org/10.3389/fphys.2019.00661.

[68] X. Jiang, T. Zeng, S. Zhang, Y. Zhang, Comparative proteomic and bioinformatic analysis of the effects of a high-grain diet on the hepatic metabolism in lactating dairy goats, PLoS One 8 (2013), https://doi.org/10.1371/journal.pone.0080698.

[69] Q. Fu, L. Pan, D. Huang, Z. Wang, Z. Hou, M. Zhang, Proteomic profiles of buffalo spermatozoa and seminal plasma, Theriogenology. 134 (2019) 74-82, https://doi. org/10.1016/j.theriogenology.2019.05.013.

[70] J. Tao, G. Zhao, X. Zhao, F. Li, X. Wu, J. Hu, Y. Zhang, Proteomic analysis of the follicular fluid of Tianzhu white yak during diestrus, Int. J. Mol. Sci. 15 (2014) 4481-4491, https://doi.org/10.3390/ijms15034481.

[71] J. Tang, W. Hu, S. Chen, R. Di, Q. Liu, X. Wang, X. He, S. Gan, X. Zhang, J. Zhang, W. Chen, M. Chu, The genetic mechanism of high prolificacy in small tail han sheep by comparative proteomics of ovaries in the follicular and luteal stages, J. Proteomics 204 (2019) 103394, https://doi.org/10.1016/j.jprot.2019.103394. 
[72] Q. Wang, Q. Zhang, Z. Gan, H. Li, Y. Yang, Y. Zhang, X. Zhao, Screening for reproductive biomarkers in Bactrian camel via iTRAQ analysis of proteomes, Reprod. Domest. Anim. 55 (2020) 189-199, https://doi.org/10.1111/rda.13607.

[73] Y. Yang, N. Zheng, X. Zhao, J. Yang, Y. Zhang, R. Han, S. Zhao, S. Li, F. Wen, J. Wang, Changes in whey proteome with lactation stage and parity in dairy cows using a label-free proteomics approach, Food Res. Int. 128 (2020) 108760, https:// doi.org/10.1016/j.foodres.2019.108760.

[74] S. Li, L. Li, Q. Zeng, J. Liu, Y. Yang, D. Ren, Quantitative differences in whey proteins among Murrah, Nili-Ravi and Mediterranean buffaloes using a TMT proteomic approach, Food Chem. 269 (2018) 228-235, https://doi.org/10.1016/j. foodchem.2018.06.122.

[75] E. Boschetti, L.E. Hernández-Castellano, P.G. Righetti, Progress in farm animal proteomics: the contribution of combinatorial peptide ligand libraries, J. Proteomics 197 (2019) 1-13, https://doi.org/10.1016/j.jprot.2019.02.005.

[76] D.M. Ribeiro, A. Salama, A.C.M. Vitor, A. Arguello, C.T. Moncau, E.M. Santos, G. Caja, J.S. de Oliveira, J.C.C. Balieiro, L.E. Hernández-Castellano, M. Zachut, M. D. Poleti, N. Castro, S.P. Alves, A.M. Almeida, The application of omics in ruminant production: a review in the tropical and sub-tropical animal production context, J. Proteomics 227 (2020) 103905, https://doi.org/10.1016/j.jprot.2020.103905.

[77] A. Marco-Ramell, A.M. De Almeida, S. Cristobal, P. Rodrigues, P. Roncada, A. Bassols, Proteomics and the search for welfare and stress biomarkers in animal production in the one-health context, Mol. BioSyst. 12 (2016) 2024-2035, https:// doi.org/10.1039/c5mb00788g.

[78] M. Zachut, M. Šperanda, A.M. De Almeida, G. Gabai, A. Mobasheri, L. E. Hernández-Castellano, Biomarkers of fitness and welfare in dairy cattle: healthy productivity, J. Dairy Res. 87 (2020) 4-13, https://doi.org/10.1017/ S0022029920000084.

[79] U. Kusebauch, L.E. Hernández-Castellano, S.L. Bislev, R.L. Moritz, C.M. Røntved, E. Bendixen, Selected reaction monitoring mass spectrometry of mastitis milk reveals pathogen-specific regulation of bovine host response proteins, J. Dairy Sci. 101 (2018) 6532-6541, https://doi.org/10.3168/jds.2017-14312.

[80] S.J. Gadher, Ł. Marczak, M. Łuczak, M. Stobiecki, P. Widlak, H. Kovarova, Proteomic landscape in central and Eastern Europe: the 9th central and eastern European proteomic conference, Poznan, Poland, Expert Rev. Proteomics. 13 (2016) 5-7, https://doi.org/10.1586/14789450.2016.1116391.

[81] M. Montowska, E. Fornal, Label-free quantification of meat proteins for evaluation of species composition of processed meat products, Food Chem. 237 (2017) 1092-1100, https://doi.org/10.1016/j.foodchem.2017.06.059.

[82] R. Raijmakers, J.V. Olsen, R. Aebersold, A.J.R. Heck, PRIME-XS, a European infrastructure for proteomics, Mol. Cell. Proteomics 13 (2014) 1901-1904, https:// doi.org/10.1074/mcp.E114.040162.

[83] M.H. Ghaffari, K. Schuh, J. Kuleš, N. Guillemin, A. Horvatić, V. Mrljak, P. D. Eckersall, G. Dusel, C. Koch, H. Sadri, H. Sauerwein, Plasma proteomic profiling and pathway analysis of normal and overconditioned dairy cows during the transition from late pregnancy to early lactation, J. Dairy Sci. 103 (2020) 4806-4821, https://doi.org/10.3168/jds.2019-17897.

[84] L. Franco-Martínez, A. Tvarijonaviciute, A. Horvatić, N. Guillemin, L.J. Bernal, R. Barić Rafaj, J.J. Cerón, M. Del C. Thomas, M.C. López, F. Tecles, S. MartínezSubiela, V. Mrljak, Changes in saliva of dogs with canine leishmaniosis: A proteomic approach, Vet. Parasitol. 272 (2019) 44-52, https://doi.org/10.1016/j. vetpar.2019.06.014.
[85] R. Baka, D. Eckersall, A. Horvatic, A. Gelemanovic, V. Mrljak, M. McLaughlin, L. V. Athanasiou, N. Papaioannou, I. Stylianaki, H.Q. Hanh, C.C. Chadwick, Z. Polizopoulou, Quantitative proteomics of cerebrospinal fluid using tandem mass tags in dogs with recurrent epileptic seizures, J. Proteomics 231 (2021) 103997, https://doi.org/10.1016/j.jprot.2020.103997.

[86] K. Yu, M. Matzapetakis, A. Horvatić, M. Terré, A. Bach, J. Kuleš, N. Yeste, N. Gómez, L. Arroyo, E. Rodríguez-Tomàs, R. Peña, N. Guillemin, A.M. de Almeida, P.D. Eckersall, A. Bassols, Metabolome and proteome changes in skeletal muscle and blood of pre-weaning calves fed leucine and threonine supplemented diets, J. Proteomics 216 (2020) 103677, https://doi.org/10.1016/j.jprot.2020.103677.

[87] Fisheries Statistics of Thailand, Department of Fisheries of the Ministry of Agriculture and Cooperatives of the Kingdom of Thailand. Bangkok, Available online at, https://www.fisheries.go.th/strategy-stat/themeWeb/books/2559/1/ yearbook_2559.pdf, 2016.

[88] C. Nakharuthai, P.M. Rodrigues, D. Schrama, S. Kumkhong, S. Boonanuntanasarn, Effects of Different Dietary Vegetable Lipid Sources on Health Status in Nile Tilapia, 2020, pp. 1-19.

[89] C.S.F. Raposo de Magalhães, M.A.C. Cerqueira, D. Schrama, M.J.V. Moreira, S. Boonanuntanasarn, P.M.L. Rodrigues, A proteomics and other omics approach in the context of farmed fish welfare and biomarker discovery, Rev. Aquac. 12 (2020) 122-144, https://doi.org/10.1111/raq.12308.

[90] S. Boonanuntanasarn, C. Nakharuthai, D. Schrama, R. Duangkaew, P.M. Rodrigues, Effects of dietary lipid sources on hepatic nutritive contents, fatty acid composition and proteome of Nile tilapia (Oreochromis niloticus), J. Proteomics 192 (2019) 208-222, https://doi.org/10.1016/j.jprot.2018.09.003.

[91] J.R. Parreira, L.E. Hernández-Castellano, A. Argüello, J. Capote, N. Castro, S. De Sousa Araújo, A.M. De Almeida, Understanding seasonal weight loss tolerance in dairy goats: a transcriptomics approach, BMC Genomics 21 (2020) 1-17, https:// doi.org/10.1186/s12864-020-06968-2.

[92] M. Palma, L.E. Hernández-Castellano, N. Castro, A. Arguëllo, J. Capote, M. Matzapetakis, A.M. De Almeida, NMR-metabolomics profiling of mammary gland secretory tissue and milk serum in two goat breeds with different levels of tolerance to seasonal weight loss, Mol. BioSyst. 12 (2016) 2094-2107, https://doi. org/10.1039/c5mb00851d.

[93] C. Kasper, D. Ribeiro, A.M. de Almeida, C. Larzul, L. Liaubet, E. Murani, Omics application in animal science-a special emphasis on stress response and damaging behaviour in pigs, Genes (Basel) 11 (2020) 1-24, https://doi.org/10.3390/ genes11080920.

[94] D.M. Ribeiro, J. Bandarrinha, P. Nanni, S.P. Alves, C.F. Martins, R.J.B. Bessa, L. Falcão-e-Cunha, A.M. Almeida, The effect of Nannochloropsis oceanica feed inclusion on rabbit muscle proteome, J. Proteomics 222 (2020) 103783, https:// doi.org/10.1016/j.jprot.2020.103783.

[95] J.R., H.M. Hammon, A. Tröscher, L. Vogel, M. Gnott, G. Kra, Y. Levin, H. Sauerwein, M. Zachut, Phosphoproteomic Analysis of Subcutaneous and Omental Adipose Tissue Reveals Increased Lipid Turnover in Dairy Cows Supplemented with Conjugated Linoleic Acid, Int. J. Mol. Sci. 22 (6) (2020) 3227, https://doi.org/10.3390/ijms22063227, 2021 Mar 22.

[96] D.M. Ribeiro, S. Planchon, C.C. Leclercq, K. Raundrup, S.P. Alves, R.J.B. Bessa, J. Renaut, A.M. Almeida, The muscular, hepatic and adipose tissues proteomes in muskox (Ovibos moschatus): differences between males and females, J. Proteomics 208 (2019) 103480, https://doi.org/10.1016/j.jprot.2019.103480. 